\title{
Spinal Cord Injury Elicits Expression of Keratan Sulfate Proteoglycans by Macrophages, Reactive Microglia, and Oligodendrocyte Progenitors
}

\author{
Leonard L. Jones ${ }^{1}$ and Mark H. Tuszynski ${ }^{1,2}$ \\ ${ }^{1}$ Department of Neurosciences, University of California-San Diego, La Jolla, California 92093, and 2Veterans Affairs \\ Medical Center, San Diego, California 92161
}

Keratan sulfate proteoglycans (KSPGs) are extracellular matrix molecules that appear to establish boundaries for axonal growth in the developing brain and spinal cord. In vitro studies confirm that KSPGs define inhibitory boundaries to extending neurites. The aim of the current study was to investigate whether KSPGs are expressed after spinal cord injury (SCI) and thereby might act as potential inhibitors of axonal growth. Adult Fischer 344 rats were subjected to spinal cord lesions, and the temporal and spatial expression of KSPGs was examined using the 5D4 monoclonal anti-KSPG antibody. In the intact spinal cord, a subpopulation of microglia expressed 5D4-KSPG throughout the white and gray matter. Within $24 \mathrm{hr}$ of injury, 5D4-KSPG immunoreactivity substantially increased and appeared on cellular profiles in close proximity to the spinal cord lesion site, peaking $3 \mathrm{~d}$ after injury. Double immunolabeling revealed that 5D4-KSPG expression arose from multiple cell types at the lesion site, including reactive microglia, macrophages, and oligodendrocyte progenitors. Astrocytes were not identified as a source of 5D4-KSPG. The robust and extensive production of 5D4-KSPG at sites of SCI precedes the expression of other putatively inhibitory proteoglycan molecules such as chondroitin sulfate proteoglycans. This is the first demonstration that KSPGs are expressed after SCI in a temporal and spatial relationship that could exert an early and important role in modulating axonal growth after $\mathrm{SCl}$.

Key words: keratan sulfate proteoglycan; extracellular matrix; spinal cord injury; macrophage; microglia; oligodendrocyte progenitor; inhibition; regeneration
Inhibitory molecules are believed to limit axonal regeneration after CNS injuries. Various inhibitory molecules, including the myelin-associated molecules NoGo and MAG (myelin-associated glycoprotein) (McKerracher et al., 1994; Filbin, 1995; Huber and Schwab, 2000) and extracellular matrix (ECM) molecules such as the chondroitin sulfate proteoglycans (CSPGs) (Levine, 1994; Fitch and Silver, 1997a; Haas et al., 1999; Lemons et al., 1999; McKeon et al., 1999; Chang et al., 2000; Thon et al., 2000; Yamaguchi, 2000; Jones et al., 2001), are thought to create a nonpermissive environment for axonal growth. An additional class of ECM molecules that is not well characterized, but is known to inhibit neurite growth in vitro, is the family of keratan sulfate proteoglycans (KSPGs).

KSPGs consist of different core proteoglycans that are individually glycosylated to varying degrees with keratan sulfate chains. These keratan sulfates are potent inhibitors of neurite outgrowth in vitro (Snow et al., 1990b; Cole and McCabe, 1991; Dou and Levine, 1995; Powell et al., 1997), suggesting that the general family of KSPGs is inhibitory to axonal growth. Although some members of this family of inhibitory ECM molecules have been characterized, the majority of studies investigating KSPG expres-

\footnotetext{
Received Dec. 5, 2001; revised March 19, 2002; accepted March 25, 2002.

This work was supported by National Institutes of Health Grant NS10927, the Veterans Administration, the Hollfelder Foundation, and the Heumann Foundation. The rabbit polyclonal rat-PDGF $\alpha$-receptor antibody was a generous gift from Dr. Bill Stallcup (Burnham Institute, La Jolla, CA). The IBA1 polyclonal antibody was a generous gift from Dr. Yoshinori Imai (National Institute of Neuroscience, Tokyo, Japan). We thank Dana Sajed for excellent technical assistance.

Correspondence should be addressed to Dr. Mark H. Tuszynski, Department of Neurosciences-0626, University of California-San Diego, 9500 Gilman Drive, La Jolla, CA 92093. E-mail: mtuszyns@ucsd.edu.

Copyright (C) 2002 Society for Neuroscience $0270-6474 / 02 / 224611-14 \$ 15.00 / 0$
}

sion in the CNS use antibodies that recognize different epitopes specific to the sulfated keratans and not to the core proteoglycans. During development, sulfated keratans are temporally and spatially located in areas in which restricted axonal growth occurs (Snow et al., 1990a; Cole and McCabe, 1991; Perris et al., 1991; Geisert and Bidanset, 1993; Seo and Geisert, 1995). For example, in the embryonic rat spinal cord, sulfated keratans are expressed specifically at the roof plate from embryonic day 12.5 (E12.5) to E13.5 (Snow et al., 1990a). This is the time point that the dorsal-most commissural neurons are extending their axons, which subsequently veer away from the roof plate and elongate dorsolaterally. Sulfated keratans are also localized in midline barrier structures in the embryonic spinal cord and hindbrain (Cole and McCabe, 1991), in boundary regions between thalamic nuclei (Geisert and Bidanset, 1993), and between the cortical barrels in the somatosensory cortex throughout development and into adulthood (Seo and Geisert, 1995). In the adult, sulfated keratans are also found on a subpopulation of microglia throughout the brain (Bertolotto et al., 1998) and spinal cord (Jander and Stoll, 1996). Sulfated keratans are also expressed in the injured CNS after cortical stab wounds in neonatal rats (Geisert and Bidanset, 1993) and in the postcomissural fornix after a lesion in adult rats (Stichel et al., 1999). However, it is not known whether expression of KSPGs, and consequently the level of sulfated keratans, is altered in the injured spinal cord.

Thus, the present study used the 5D4 antibody to examine the expression pattern and cellular sources of KSPGs in the injured spinal cord. To date, the 5D4 monoclonal antibody has been used most extensively to evaluate KSPG expression in the CNS (Snow et al., 1990a; Cole and McCabe, 1991; Perris et al., 1991; Bertolotto et al., 1993, 1995, 1998; Jander and Stoll, 1996; Miller et al., 
1997; Hirsch and Bahr, 1999; Stichel et al., 1999; Jander et al., 2000). The 5D4-KSPG antibody recognizes a unique keratan sulfate epitope (Caterson et al., 1983) that is not recognized by antibodies specific to previously described KSPG species (Miller et al., 1997). At present, the core proteoglycan associated with this particular keratan sulfate moiety remains unknown, and thus 5D4-KSPG immunoreactivity identifies one, and potentially several, unique KSPG molecules in the CNS. Findings from this study reveal a rapid and robust increase in expression of 5D4KSPG in the injured spinal cord and demonstrate that reactive microglia, macrophages, and oligodendrocyte progenitors are cellular sources of 5D4-KSPG after spinal cord injury (SCI).

\section{MATERIALS AND METHODS}

Animal subjects and surgery. Adult female Fischer 344 rats (160-200 gm) were the subjects of this study. National Institutes of Health guidelines for laboratory animal care and safety were strictly followed. Animals had access to food and water ad libitum throughout the study. All surgery was performed under anesthesia with a combination $(2 \mathrm{ml} / \mathrm{kg})$ of ketamine $(25 \mathrm{mg} / \mathrm{ml})$, rompun $(1.3 \mathrm{gm} / \mathrm{ml})$, and acepromazine $(0.25 \mathrm{mg} / \mathrm{ml})$. A total of 26 rats were used in this study at postinjury time points as follows: $1 \mathrm{~d}(n=4), 3 \mathrm{~d}(n=4), 7 \mathrm{~d}(n=4), 2$ weeks $(n=4), 4$ weeks $(n=3)$, and 8 weeks $(n=4)$. Nonlesioned, intact animals were used as controls $(n=3)$.

To study the temporal expression of 5D4-KSPG after SCI, a dorsal column spinal cord lesion was performed at the $\mathrm{C} 3$ level as described previously (Weidner et al., 2001). Briefly, rats were deeply anesthetized and C3 laminectomies were performed. A tungsten wire knife (David Kopf Instruments, Tujunga, CA) was stereotaxically positioned at the spinal dorsal midline, moved $0.6 \mathrm{~mm}$ to the left of the midline, and lowered to a depth of $1.1 \mathrm{~mm}$ ventral to the dorsal surface. The tip of the knife was extruded, forming a 2.25 -mm-wide wire arc that was raised 2 $\mathrm{mm}$ and simultaneously met by a blunt glass rod that added compression from above to ensure full transection of the tissue. This lesioned the dorsal columns bilaterally, including the corticospinal tract (CST). The wire arc was retracted back into the wire knife device and was removed from the spinal cord.

Tissue processing. After induction of deep anesthesia, animals were transcardially perfused with $4 \%$ paraformaldehyde in $0.1 \mathrm{M}$ phosphate buffer. Spinal cords were dissected, postfixed overnight at $4^{\circ} \mathrm{C}$, and then transferred to $30 \%$ sucrose in phosphate buffer for $2-5 \mathrm{~d}$. Spinal cords were sagitally sectioned on a cryostat set at $35 \mu \mathrm{m}$. One-in-seven sections were mounted on gelatin-coated glass slides for Nissl staining. Remaining sections were serially collected into 24 well plates for immunohistochemical labeling.

Immunohistochemistry. To determine the relative amount and distribution of 5D4-KSPG deposition over time, immunolabeling was performed $1 \mathrm{~d}, 3 \mathrm{~d}, 7 \mathrm{~d}, 2$ weeks, 4 weeks, and 8 weeks after SCI. All sections were processed free-floating, and endogenous peroxidase activity was blocked with $0.6 \%$ hydrogen peroxide as described previously (Grill et al., 1997). Nonspecific antibody reactions were blocked with 5\% horse serum (for monoclonal antibodies) or $5 \%$ goat serum (for polyclonal antibodies) for $1 \mathrm{hr}$ at room temperature. Sections were incubated overnight at $4^{\circ} \mathrm{C}$ with the mouse monoclonal 5D4 anti-KSPG antibody (1:1000; Seikagaku America, Falmouth, MA). After washing in Trisbuffered saline (TBS), sections were incubated with biotinylated conjugated IgG anti-mouse secondary antibody (1:200; Vector Laboratories Inc., Burlingame, CA) for $1 \mathrm{hr}$ at room temperature followed by $1 \mathrm{hr}$ of incubation in avidin-biotinylated peroxidase complex (1:100; Elite Kit; Vector Laboratories Inc.) at room temperature. A primary antibody omission control was included to exclude nonspecific binding of the secondary antibody. Diaminobenzidine $(0.05 \%)$ and nickel chloride $(0.04 \%)$ were used as chromagens, with reactions sustained for $3 \mathrm{~min}$ at room temperature. The sections were mounted on gelatin-coated slides, dehydrated, and coverslipped with DPX mounting medium (BDH Laboratory Supplies, Poole, UK).

Quantification of spinal cord areas exhibiting 5D4-KSPG immunoreactivity was performed using NIH Image software. Two regions of the spinal cord were evaluated for regulation of 5D4-KSPG immunoreactivity after SCI: (1) at the lesion site and (2) in the degenerating dorsal white matter rostral to the lesion epicenter. At the lesion site, standardized areas for sampling in two sections from each animal in each group were identified as a $600 \mu \mathrm{m}$ wide band of spinal cord adjoining the cord-lesion interface in each section (see Fig. $4 C$ ). In the dorsal white matter, standardized areas for sampling in two sections from each animal in each group were identified as a $250 \mu \mathrm{m}^{2}$ area of tissue located $5 \mathrm{~mm}$ rostral to the lesion site in each section (see Fig. $4 E$ ). The mean number of pixels containing immunolabeled reaction product in the sampled area was measured and divided by the area of the sampled region to obtain a mean density value for the lesioned tissue. Values were subtracted from background immunolabel intensity, as measured in a separate $1 \mathrm{~mm}^{2}$ area of tissue located $5 \mathrm{~mm}$ caudal to the lesion site, or as measured in a separate $250 \mu \mathrm{m}^{2}$ area of tissue located $5 \mathrm{~mm}$ rostral to the lesion site in the ventral white matter, respectively. Mean values for each animal were then compared. Light intensity and thresholding values were maintained at constant levels for all analyses.

In addition, immunofluorescent double labeling was performed to identify cellular sources of 5D4-KSPG. After blocking nonspecific antibody reactions with $5 \%$ goat serum for $1 \mathrm{hr}$ at room temperature, free-floating sections were incubated overnight at $4^{\circ} \mathrm{C}$ with the mouse monoclonal 5D4 anti-KSPG (1:1000) and simultaneously with one of the following rabbit polyclonal antibodies: anti-rat platelet-derived growth factor (PDGF) $\alpha$-receptor (1:1000; gift from Dr. Bill Stallcup, Burnham Institute, La Jolla, CA), a cellular marker shown previously to be specific to oligodendrocyte progenitors (Nishiyama et al., 1996a,b); anti-rat ionized calcium-binding adapter molecule 1 (IBA1; 1:1000; gift from Dr. Yoshinori Imai, National Institute of Neuroscience, Tokyo, Japan), specific for microglia/macrophages (Ito et al., 1998; Kloss et al., 1999; Ohsawa et al., 2000); and anti-bovine glial fibrillary acidic protein (GFAP; 1:750; Dako, Glostrup, Denmark), specific to astrocytes (Palfreyman et al., 1979). Sections were washed with TBS and incubated with Alexa 488 fluorophore goat anti-rabbit antibody (1:150; Molecular Probes, Eugene, OR) and Alexa 594 fluorophore goat anti-mouse antibody (1:150; Molecular Probes) for $2.5 \mathrm{hr}$ at room temperature. The sections were then washed with TBS, mounted on uncoated slides, and coverslipped with Fluoromount G (Southern Biotechnology Associates, Inc., Birmingham, AL). Primary antibody omission controls were performed to control for nonspecific binding. Fluorescent visualization was performed on an Olympus confocal microscope with an omnichrome series 43 argon-krypton laser and appropriate filter sets (Olympus America, Melville, NY). Fluorescent bleed-through controls were performed to test for detection of Alexa 488 fluorophore in the 594 channel, using tissue labeled only with Alexa 488 fluorophore and then evaluating for bleed-through in the 594 channel. The same method was used to assure the absence of Alexa 594 fluorophore in the 488 channel.

Quantification of IBA1-labeled microglia that also express 5D4-KSPG in the intact spinal cord was performed. The total number of IBA1labeled cells was counted in four randomly chosen, three dimensional regions $(350 \times 350 \times 20 \mu \mathrm{m})$ in both the white and gray matter (two regions in the dorsal white matter and two regions in the ventral white matter) (see Fig. 4A) in tissue from three intact animals; two sections per animal were examined. The total number of IBA1/5D4-KSPG doublelabeled cells was counted in these same regions and the percentage of IBA1/5D4-KSPG-expressing microglia was calculated. Double labeling for IBA1 and 5D4-KSPG was performed as described above. After completion of IBA1/5D4-KSPG labeling, sections were incubated for 15 min at room temperature in TOTO-3 (1:5000) to stain all nuclei and then washed three times with TBS. Individual $20 \mu \mathrm{m}$ confocal $\mathrm{Z}$-scans of IBA1 in the 488 channel, 5D4-KSPG in the 594 channel, and TOTO-3 in the 647 channel were merged to visualize IBA1-labeled microglia and IBA1/5D4-KSPG double-labeled microglia. TOTO-3 nuclear stain was used to associate cellular processes with cell nuclei (see Fig. 4A). Only cellular profiles associated with a TOTO-3-labeled nucleus were quantified. In the intact spinal cord, all 5D4-KSPG cells were IBA1 doublelabeled (see Results).

Statistics. Multiple group comparisons were made by ANOVA and post hoc Fisher's tests, using a significance level of 95\%. Data are presented as mean \pm SEM.

\section{RESULTS}

\section{D4-KSPG is expressed by microglia in the intact spinal cord}

In the intact spinal cord, 5D4-KSPG was expressed throughout the white and gray matter (Fig. 1). Cellular markers for microglia, astrocytes, and oligodendrocyte progenitors were used to determine the cellular sources of 5D4-KSPG in the intact spinal cord. Double-label confocal microscopy 


\section{Intact Spinal Cord}
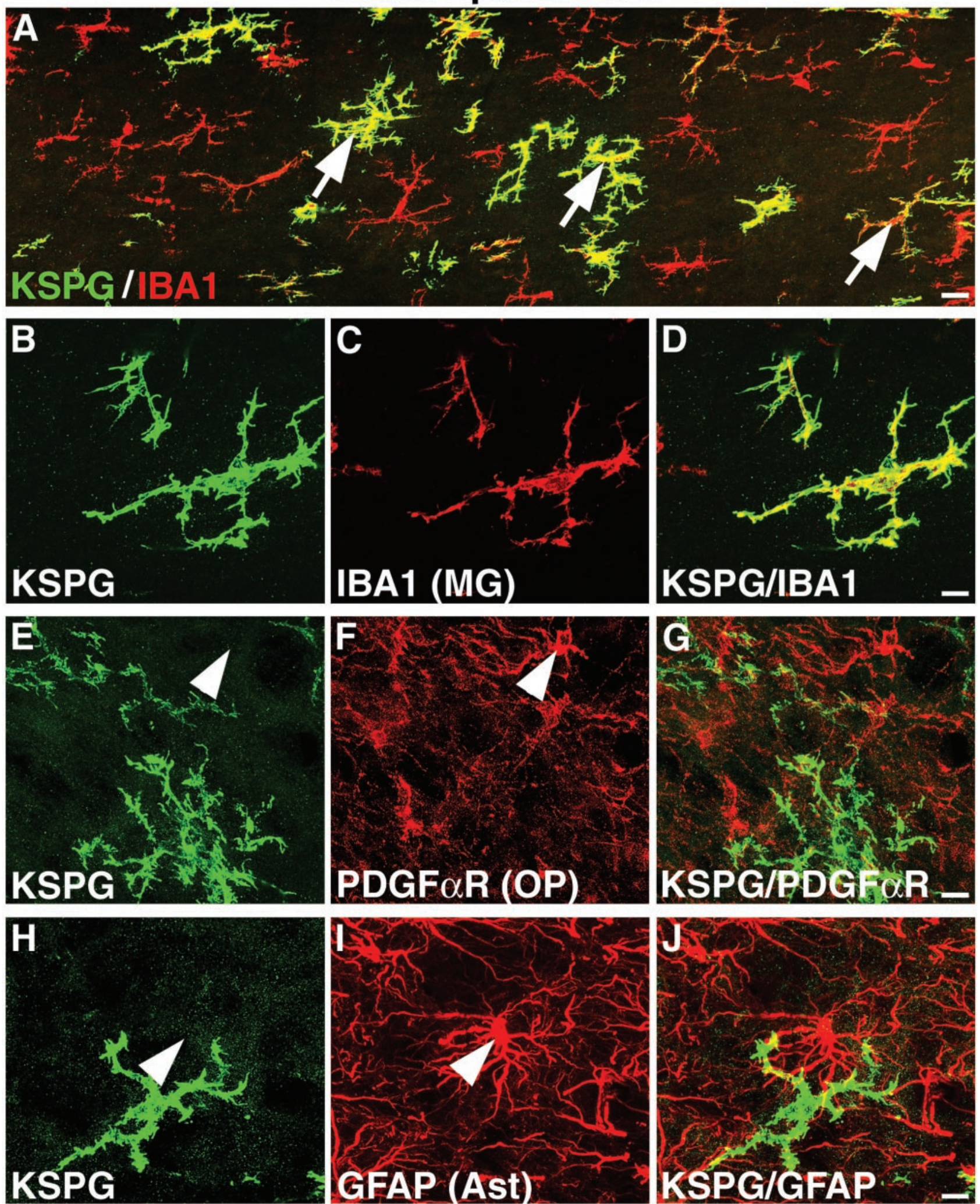

Figure 1. KSPG expression by microglia in the intact spinal cord. 5D4-KSPG is expressed throughout the intact spinal cord on a subpopulation of microglia but not on oligodendrocyte progenitors and astrocytes. $A$, Composite of three confocal images taken from the dorsal white matter. 5D4-KSPG, green; microglial/macrophage marker IBA1, red. Arrows indicate examples of ramified microglia expressing 5D4-KSPG. Scale bar, 135 $\mu$ m. $B-D$, High magnification of 5D4-KSPG and IBA1 microglia $(M G)$. 5D4-KSPG immunoreactivity encompasses the soma and cell processes. Scale bar, $5 \mu$ m. $E-G$, Arrowheads indicate the lack of colocalization of 5D4-KSPG and PDGF $\alpha$-receptor-labeled oligodendrocyte progenitors $(O P)$; arrowheads in $H$-J indicate no association of 5D4-KSPG with GFAP-labeled astrocytes (Ast). Scale bar, $11 \mu \mathrm{m}$. 
showed that microglia expressed 5D4-KSPG throughout the intact spinal cord (Fig. $1 A-D$ ). In gray matter and white matter, respectively, $46.1 \pm$ $5.3 \%$ and $42.9 \pm 5.4 \%$ of IBA1-labeled microglia expressed 5D4-KSPG (see Fig. 4A,B). Resident CNS glial cells other than microglia did not express 5D4-KSPG, including PDGF $\alpha$-receptor-labeled oligodendrocyte progenitor cells (Fig. $1 E-G$ ) and GFAP-labeled astrocytes (Fig. $1 H-J)$.

\section{Expression of KSPG is significantly increased after SCI}

As soon as $24 \mathrm{hr}$ after injury, an increase of 5D4-KSPG immunoreactivity was observed on cellular profiles in the injured tissue surrounding the lesion (Fig. 2B) compared with intact tissue. Particularly dense 5D4-KSPG immunoreactivity was exhibited on many cells bearing oblong profiles (Fig. 2B, inset). By $3 \mathrm{~d}$ after injury, substantial upregulation of 5D4-KSPG had occurred throughout the injured tissue and completely surrounded the lesion site (Fig. 2C). Dense labeling was present in a $300-\mu \mathrm{m}$-wide band around the lesion margin. 5D4-KSPG immunoreactivity was also present on cellular profiles located $0.3-1.0 \mathrm{~mm}$ from the lesion site (Fig. 2C, inset); these cells bore shorter processes and a less ramified morphology compared with 5D4-KSPG-labeled cells in intact tissue. Elevated 5D4-KSPG labeling was still present $7 \mathrm{~d}$ after injury, with the most intense labeling remaining in tissue immediately surrounding the lesion (Fig. 2D). A distinct reduction in 5D4-KSPG labeling was evident 2 weeks after injury, and 5D4-KSPG immunoreactivity no longer formed a dense, continuous border surrounding the lesion (Fig. 2E). However, strong 5D4-KSPG labeling remained prominent on cellular profiles with irregular somata and stubby processes and was observed up to $1 \mathrm{~mm}$ from the border of the lesion (Fig. 2E, inset). 5D4-KSPG immunoreactivity continued to decrease around the lesion site 4 weeks after injury but remained present in regions of degenerating tissue (Fig. $2 F$ ). By 8 weeks after injury, increased 5D4-KSPG immunoreactivity was present only on cells in close proximity to the lesion site (Fig. $2 G$, inset). 5D4-KSPG cells with ramified morphology were also present in tissue remote from the injury site, resembling expression patterns observed in the intact spinal cord.

Quantification of spinal cord tissue bearing increased 5D4-KSPG immunolabeling around lesion sites, using NIH Image, demonstrated that KSPG expression peaked $3 \mathrm{~d}$ after injury and then gradually reapproached basal levels over the following 7 weeks (Fig. $3 C, D ; p<0.0001$ ).

\section{KSPG is expressed by reactive microglia and macrophages in the injured spinal cord}

Both reactive microglia and macrophages were identified as sources of 5D4-KSPG after SCI, using double immunofluorescent microscopy and morphological analysis. Currently, there are no cellular markers that distinguish microglia from macrophages, and the combination of a microglial/macrophage cellular marker (in this case IBA1) and morphological analysis is the optimal method for distinguishing these two cell types. Morphological criteria for macrophages include ameboid, oblong cell bodies with ruffled membranes and short cytoplasmic extensions (Kreutzberg, 1996). Microglia were identified based on their highly ramified structure and were considered reactive microglia when they exhibited stout, partially retracted processes extending from the cell perikarya [Kreutzberg (1996), their Fig. 1].

Confocal images of 5D4-KSPG immunolabeling, merged with images of IBA1 immunolabeling, demonstrated that KSPG is highly colocalized on the surface of macrophages and reactive microglia as soon as $1 \mathrm{~d}$ after injury (Fig. 5A-C). 5D4-KSPG macrophages were located primarily in the injured tissue in closest proximity to the lesion site, whereas reactive microglia expressing 5D4-KSPG were seen up to $1 \mathrm{~mm}$ from the border of the lesion. Thin-section confocal images $(1 \mu \mathrm{m})$ reconstituted through a $20 \mu \mathrm{m}$ Z-stack revealed that punctate 5D4-KSPG labeling was associated with the cellular surface of macrophages and reactive microglia. At this time point of $1 \mathrm{~d}$ after injury, all 5D4-KSPG-labeled cells also exhibited IBA1 immunoreactivity. At $3 \mathrm{~d}$ after injury, increased quantities of IBA1-labeled cells and of IBA1/5D4-KSPG double-labeled cells were observed adjacent to the injury site. At $7 \mathrm{~d}$ after lesion, the number of 5D4-KSPG-expressing macrophages further increased at the lesion site relative to $3 \mathrm{~d}$ after injury (Fig. 5G-I); however, IBA1-labeled cells that did not coexpress 5D4-KSPG at this time point also substantially increased in number. Hence, although a greater number of 5D4-KSPGexpressing macrophages were observed by $7 \mathrm{~d}$ after injury, the overall proportion of macrophages expressing 5D4-KSPG was reduced. Most macrophages that did not express 5D4-KSPG were located within the lesion cavity itself and in injured tissue directly bordering the lesion (Fig.
6). 5D4-KSPG-expressing macrophages were only found in injured tissue adjacent to the lesion border, but not in the lesion cavity itself. Evaluation of high-magnification confocal Z-stacks and serial images revealed punctate 5D4-KSPG immunoreactivity specific to the outer surface of macrophages (Fig. 7). By 2 weeks after injury, fewer 5D4-KSPG-labeled macrophages were detected compared with $7 \mathrm{~d}$, but macrophages accounted for the majority of 5D4-KSPG-expressing cells at both time points. By 4 and 8 weeks after injury, 5D4-KSPG-labeled macrophages were only present in spinal cord regions with continuing tissue degeneration and cell death (e.g., dorsal column projections rostral to the lesion). At these later time points, however, many 5D4-KSPG/IBA1 doublelabeled cells regained a ramified morphology. By 8 weeks after SCI, most 5D4-KSPG/IBA1 double-labeled cells resembled the ramified 5D4KSPG/IBA1 microglia observed in intact tissue (Fig. $5 J-L$ ).

\section{Oligodendrocyte progenitors, but not astrocytes, are an additional source of KSPG after SCI}

In addition to IBA1-immunoreactive cells, PDGF $\alpha$-receptor-labeled oligodendrocyte progenitor cells also expressed 5D4-KSPG (Fig. 8). 5D4-KSPG-labeled oligodendrocyte progenitors exhibited multiple, thin, long, and intertwined processes at the lesion site. These cells typically exhibited 5D4-KSPG immunoreactivity both on the perikaryon and on extending processes (Fig. $8 D-F$ ). In contrast to the graded expression of 5D4-KSPG by reactive microglia and macrophages, oligodendrocyte progenitors demonstrated a transient burst of 5D4-KSPG expression that contributed substantially to overall 5D4-KSPG deposition $3 \mathrm{~d}$ after SCI. 5D4-KSPG immunoreactivity on these glial cells was considerably diminished $7 \mathrm{~d}$ after injury and was present on only rare cellular profiles 2 weeks after injury. At 4 and 8 weeks after SCI, oligodendrocyte progenitors no longer displayed colocalization with 5D4-KSPG labeling.

Immunofluorescent double-labeling demonstrated that GFAP-labeled astrocytes did not colocalize to 5D4-KSPG in the injured tissue (Fig. $8 G-I)$. 5D4-KSPG-labeled processes were occasionally located near reactive astrocytes, but rotation of scanned high-resolution confocal images failed to disclose an association of 5D4-KSPG labeling either with astrocyte surfaces or with cell bodies at any time point of this study ( $1 \mathrm{~d}$ to 8 weeks after SCI). Thus, astrocytes did not appear to constitute a source of 5D4-KSPG expression in either the intact or lesioned spinal cord.

\section{Prolonged KSPG expression also occurs in the degenerating dorsal columns remote from the lesion site}

5D4-KSPG expression also increased in the ascending dorsal column sensory projection, measured $5 \mathrm{~mm}$ rostral to the lesion site (Fig. 3). An increase in KSPG labeling was evident by $3 \mathrm{~d}$ after lesion, peaked after 2 weeks (Fig. 4E,F) $(p<0.0001)$, and continued for 4 weeks (Fig. $3 D-F)$. By 8 weeks, levels had decreased considerably in comparison with the preceding weeks but remained moderately elevated. However, 5D4-KSPG immunolabeling was not detectably increased in the degenerating dorsal corticospinal projection, measured $5 \mathrm{~mm}$ caudal to the lesion site, or in the ventral CST either rostral or caudal to the lesion site.

Cellular colocalization studies were performed to identify the source of KSPG expression in the degenerating dorsal column white matter 5 $\mathrm{mm}$ from the lesion site (Fig. 9). 5D4-KSPG immunoreactivity was associated with ramified and reactive microglia (Fig. $9 B-D$ ). However, only occasional oligodendrocyte progenitors exhibited colocalization with KSPG (Fig. 9E-G), in distinction to the frequent association of 5D4-KSPG immunoreactivity with oligodendrocyte progenitors observed at the lesion site. GFAP-labeled astrocytes did not colocalize with 5D4-KSPG (Fig. 9H-J). In addition, a considerable amount of 5D4KSPG immunofluorescence in degenerating white matter failed to associate with any of the cellular markers used in this study, suggesting that an additional cell type, possibly oligodendrocytes, also contributes to 5D4-KSPG expression after SCI.

\section{DISCUSSION}

The preceding findings reveal for the first time that KSPGs are expressed after SCI in a temporal and spatial distribution pattern that could significantly influence axonal regeneration. In addition, we identify for the first time that macrophages and oligodendrocyte progenitor cells are significant sources of this family of putatively inhibitory ECMs. 


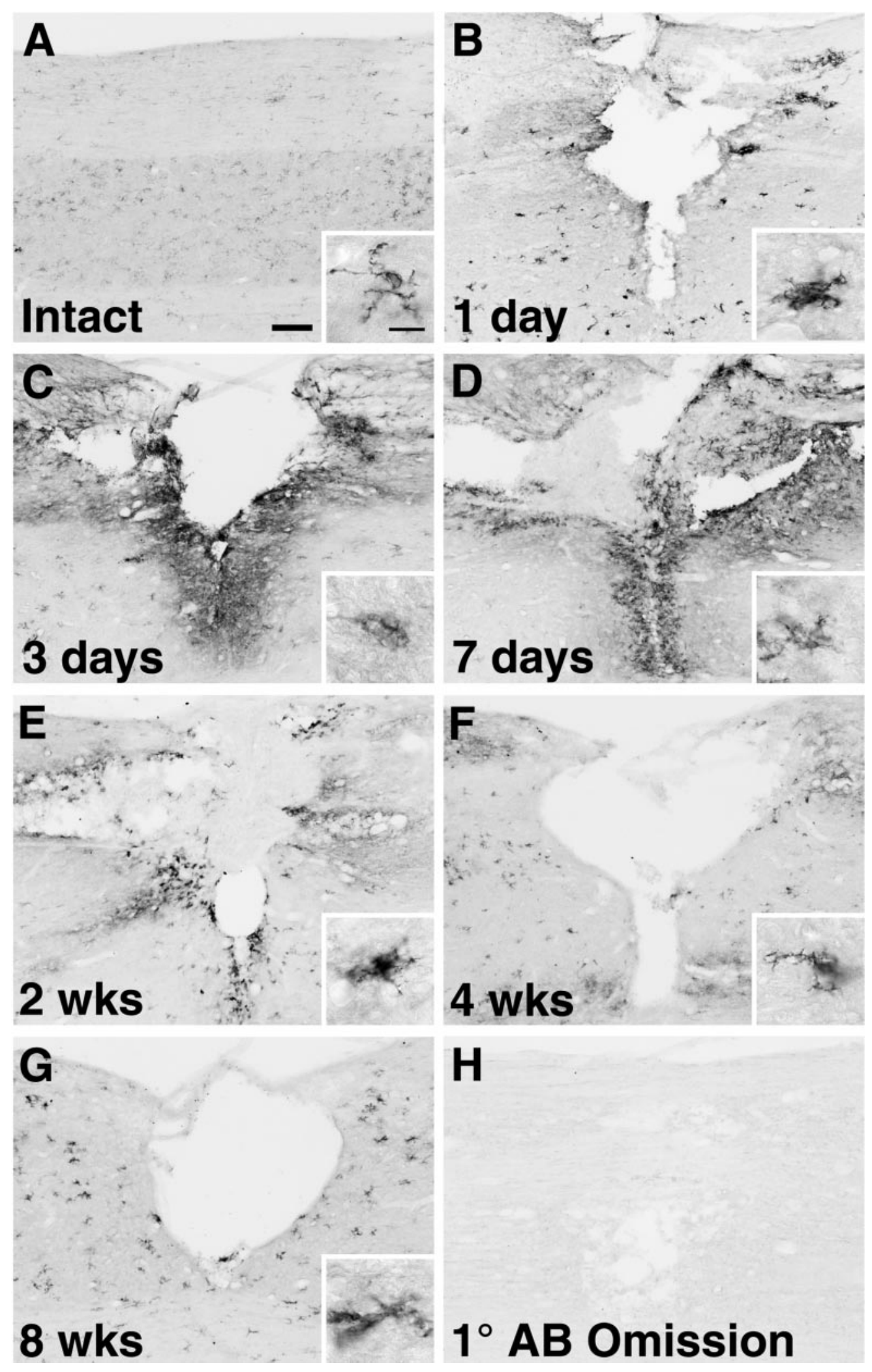

Figure 2. Time course of KSPG expression after SCI. A, Constitutive 5D4-KSPG expression is seen throughout the white and gray matter of the intact spinal cord. The high-magnification inset in $A$ shows that 5D4-KSPG label is present on highly ramified cellular profiles. $B$, At $1 \mathrm{~d}$ after injury, 5D4-KSPG is upregulated on cellular profiles in close proximity to the lesion. Insets in $B$ and $C$, Cells that display increased 5D4-KSPG immunoreactivity have retracted cellular processes compared with intact tissue. $C$, At $3 \mathrm{~d}$ after injury, strong upregulation of 5D4-KSPG is observed throughout lesioned tissue. $D-G, 5 \mathrm{D} 4-\mathrm{KSPG}$ labeling remains highly elevated at $7 \mathrm{~d}$ and then gradually declines in the following weeks. Insets in $D-G$, At the later time points, 5D4-KSPG cellular profiles become progressively more ramified. By 8 weeks, these cells resemble 5D4-KSPG-labeled cells in intact tissue but persist with thicker, shorter processes that are more densely labeled. $H$, The primary antibody omission control $\left(1^{\circ} \mathrm{AB}\right.$ Omission) exhibits only low-level background staining. Sections are positioned so that the left side is rostral to the lesion. Scale bars: Full-size panels, $177 \mu \mathrm{m}$; insets, $9 \mu \mathrm{m}$. 

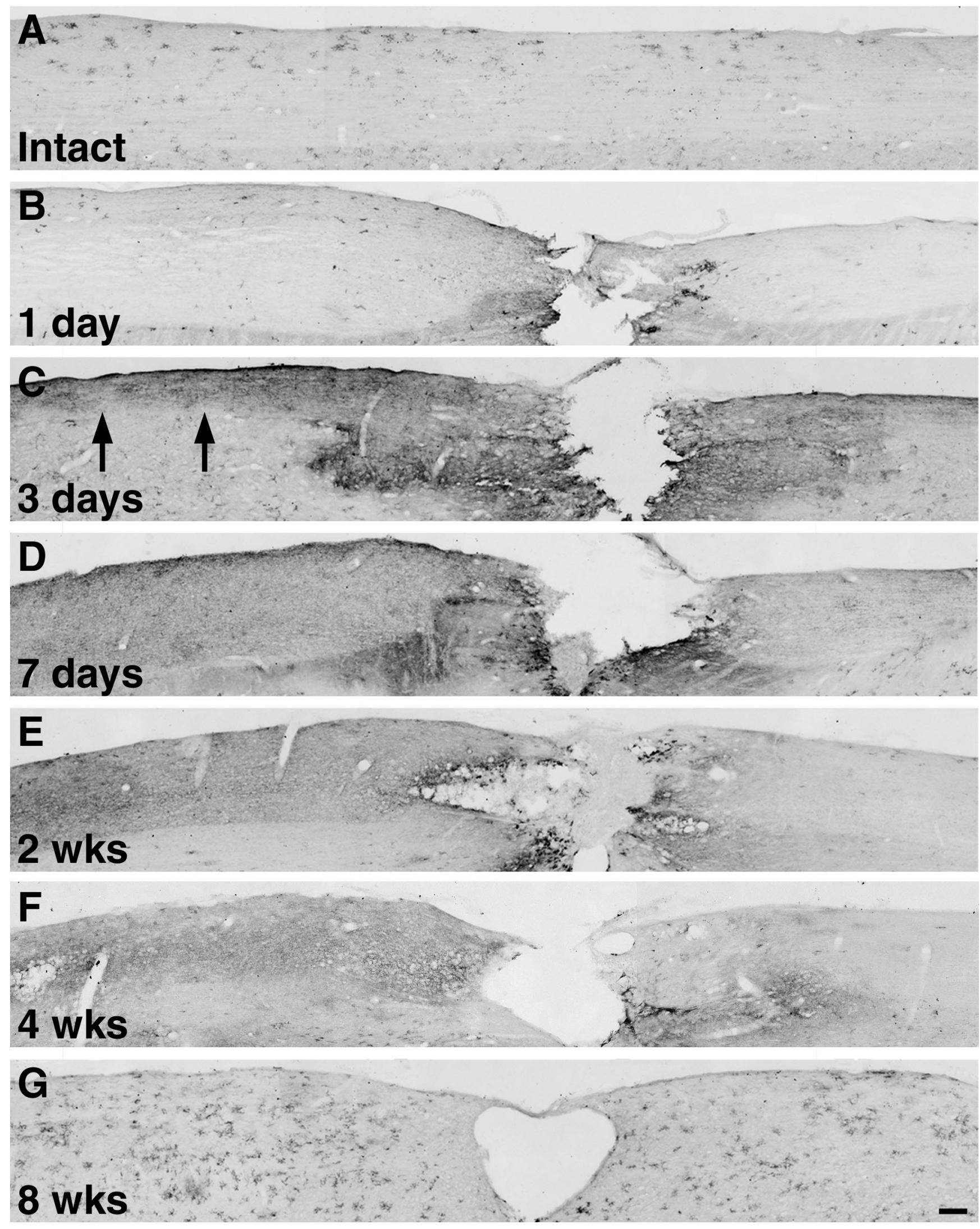

Figure 3. KSPG expression in the degenerating white matter rostral to the lesion site. $A, B, 5 \mathrm{D} 4-\mathrm{KSPG}$ levels in the dorsal white matter rostral to the lesion site remain unchanged $24 \mathrm{hr}$ after injury compared with the intact tissue. $C$, At $3 \mathrm{~d}$ after injury, increased levels of 5D4-KSPG extend into the dorsal white matter (arrows), past regions of tissue that directly surround the lesion site. $D-F, 5 \mathrm{D} 4-\mathrm{KSPG}$ levels continue to increase and remain elevated over the following 3 weeks in the dorsal white matter. $G$, By 8 weeks, levels have considerably decreased in comparison with the preceding weeks but remain moderately elevated. Scale bar, $200 \mu \mathrm{m}$. 


\section{Quantification of KSPG}
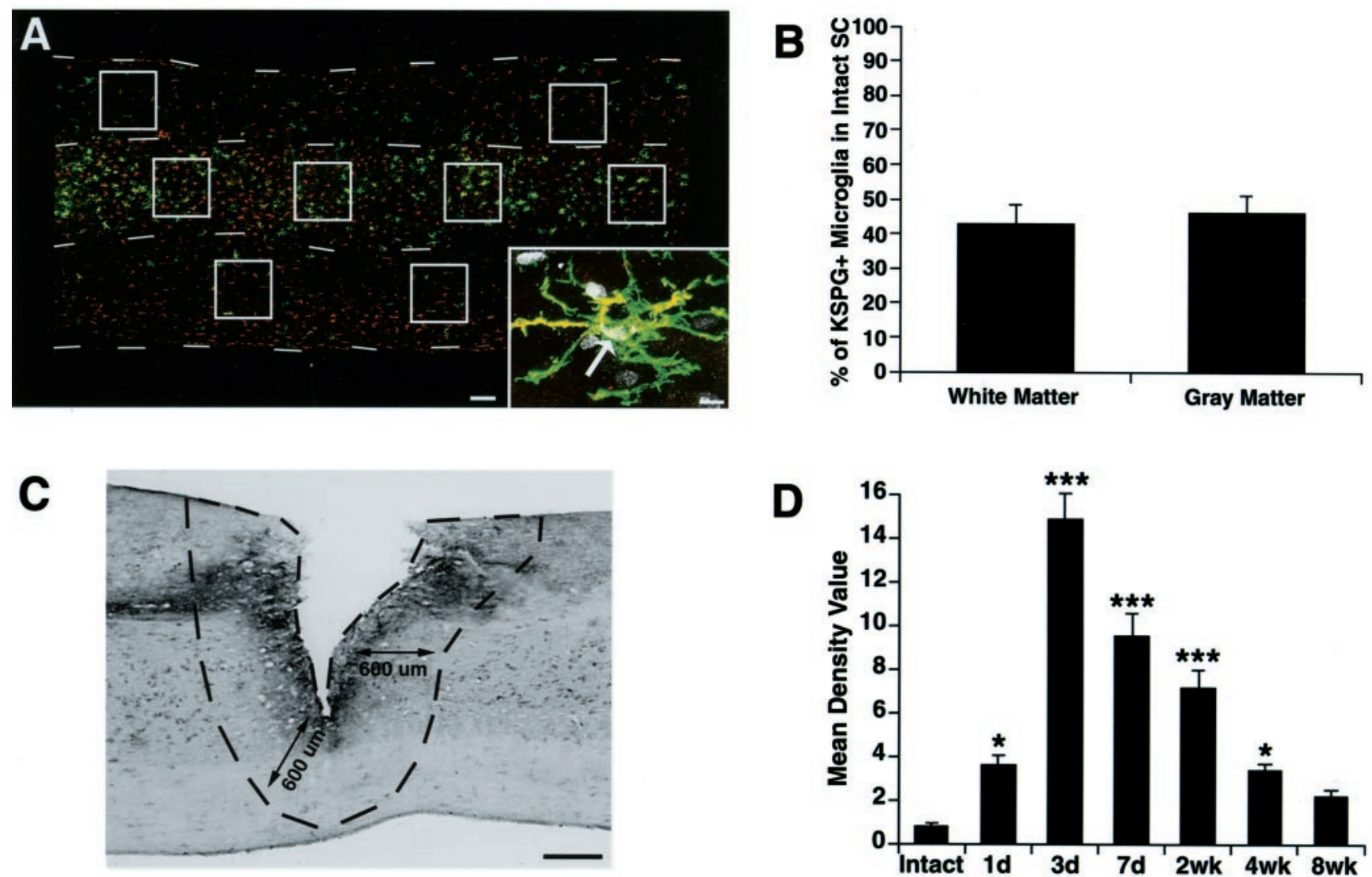

D
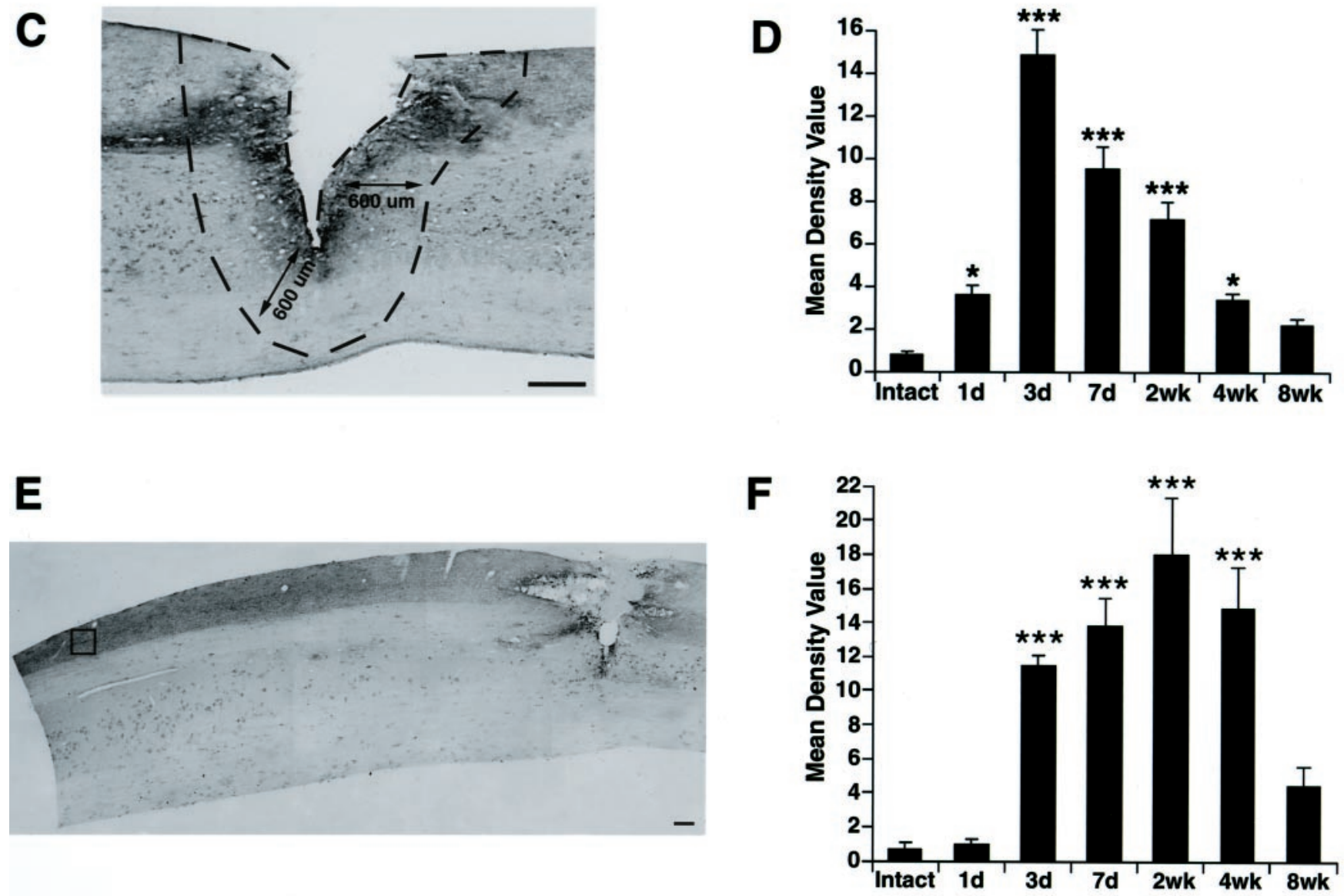

Figure 4. Quantification of KSPG. A, The percentage of 5D4-KSPG-expressing microglia in the intact spinal cord was identified by cell counts in four random regions in both the white and gray matter, as indicated by white boxes. Individual $20 \mu \mathrm{m}$ confocal Z-scans of IBA1 (red), 5D4-KSPG (green), and TOTO-3 nuclear stain (white; only seen in the inset) were merged to visualize IBA1-labeled microglia and to quantify the proportion of cells that expressed 5D4-KSPG. Inset in A, A 5D4-KSPG-expressing microglial cell. The arrow indicates a TOTO-3-labeled nucleus. Dashed white lines indicate the outer border of spinal cord and white/gray matter interface. 5D4-KSPG/IBA1 colocalization is yellow. Cell counts were determined by confirmation of a cell nucleus associated with cellular processes. Scale bars: $A, 140 \mu \mathrm{m}$; inset in $A, 8 \mu \mathrm{m}$. B, Forty-three percent of IBA1-expressing microglia also expressed 5D4-KSPG in the intact white matter, and $46 \%$ of IBA1-labeled cells expressed 5D4-KSPG in the intact gray matter. $C$, $E$, Two regions of the spinal cord were evaluated for regulation of 5D4-KSPG immunoreactive density after SCI: (1) the lesion site and (2) the degenerating dorsal white matter rostral to the lesion epicenter. At the lesion site, standardized areas for sampling were identified as a $600-\mu \mathrm{m}$-wide band of spinal cord adjoining the cord-lesion interface in each section (indicated with dashed lines). In the dorsal white matter, standardized areas for sampling were identified as a $250 \mu \mathrm{m}^{2}$ area of tissue located $5 \mathrm{~mm}$ rostral to the lesion site in each section. An example of 5D4-KSPG immunolabeling $3 \mathrm{~d}$ after SCI $(C$, scale bar, $360 \mu \mathrm{m})$ and of 5D4-KSPG labeling in the dorsal white matter rostral to the lesion site 2 weeks after SCI $(E$, scale bar, $200 \mu \mathrm{m})$, respectively. $D$, 5D4-KSPG labeling peaks $3 \mathrm{~d}$ after injury and then gradually declines, approaching basal levels. ANOVA multiple-group analysis; $p<0.0001$. Asterisks indicate a significant difference from intact subjects. $F, 5 \mathrm{D} 4-\mathrm{KSPG}$ labeling in the degenerating white matter peaks 2 weeks after SCI. ANOVA multiple-group analysis; $p<0.0001$. Asterisks indicate a significant difference from intact subjects. 
KSPG
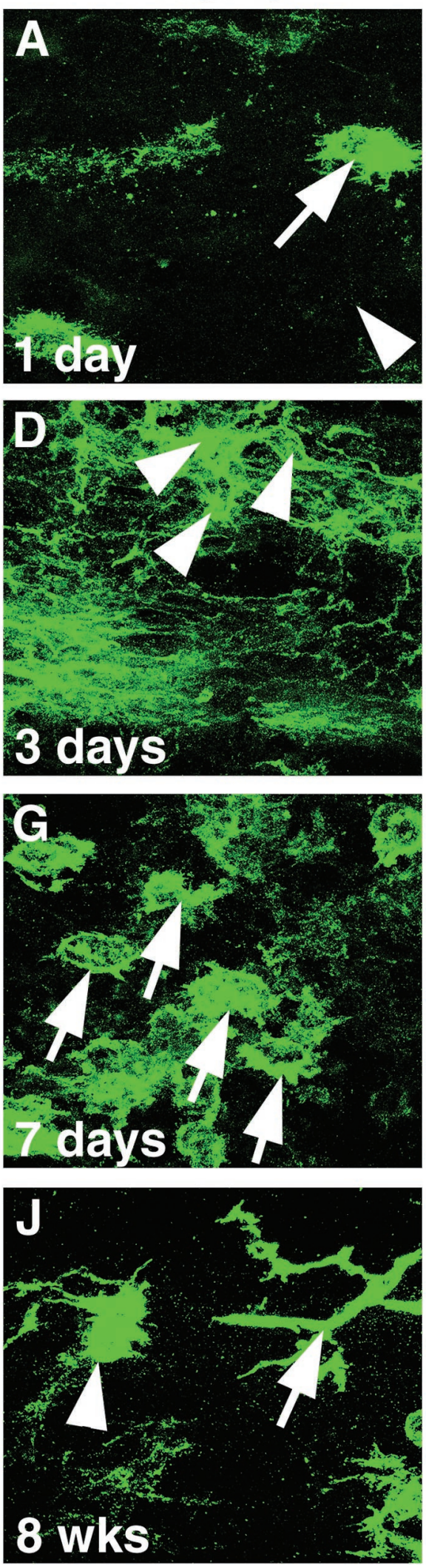

IBA1
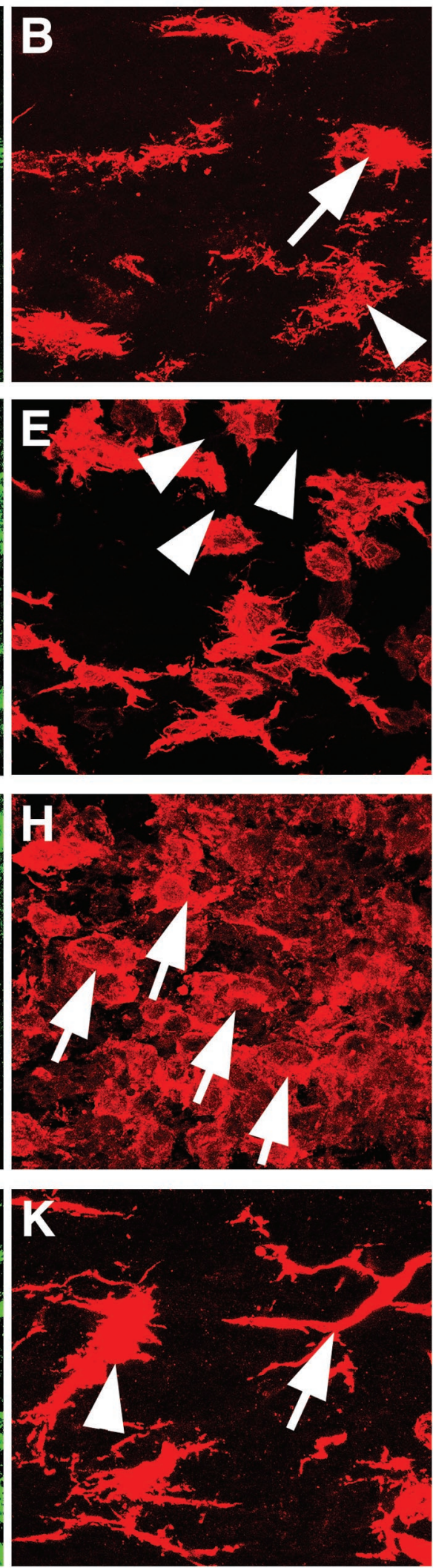

KSPG/IBA1
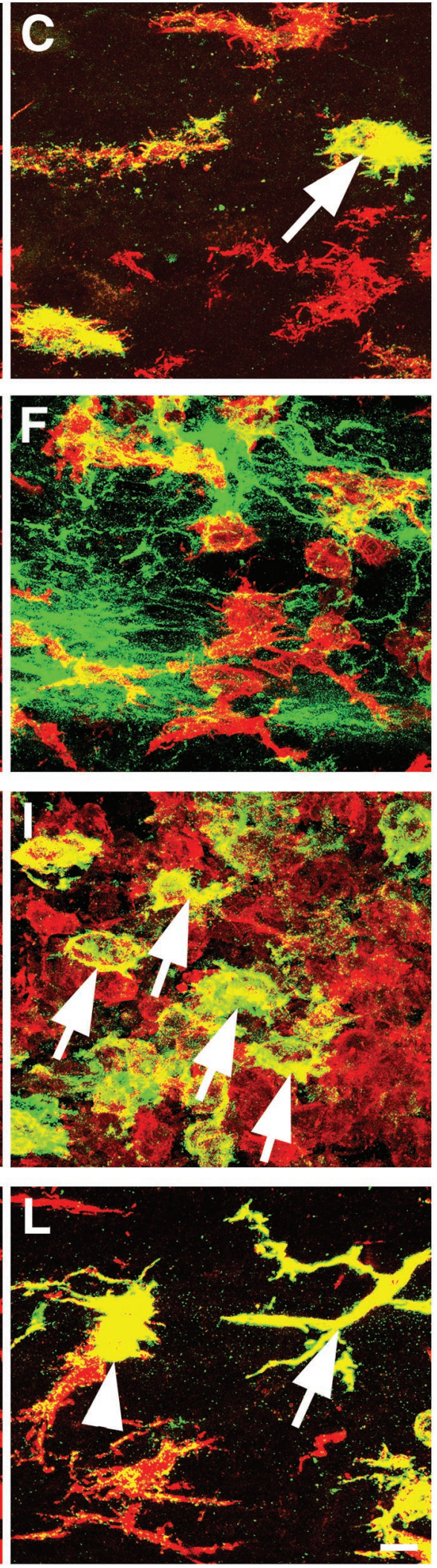

Figure 5. KSPG is produced by macrophages after SCI. $A-C$, Colocalization studies using Z-stack confocal images for KSPG and IBA1 demonstrate 5D4-KSPG expression by macrophages and reactive microglia $1 \mathrm{~d}$ after injury. 5D4-KSPG immunoreactivity is seen surrounding the surface of some macrophages (arrows). 5D4-KSPG-labeled macrophages have oblong cell bodies and numerous short, cytoplasmic protrusions. Some IBA1-labeled cells are devoid of 5D4-KSPG expression (arrowheads). D-F, At $3 \mathrm{~d}$ after SCI, a cell type that is IBA1-negative also expresses (Figure legend continues.) 


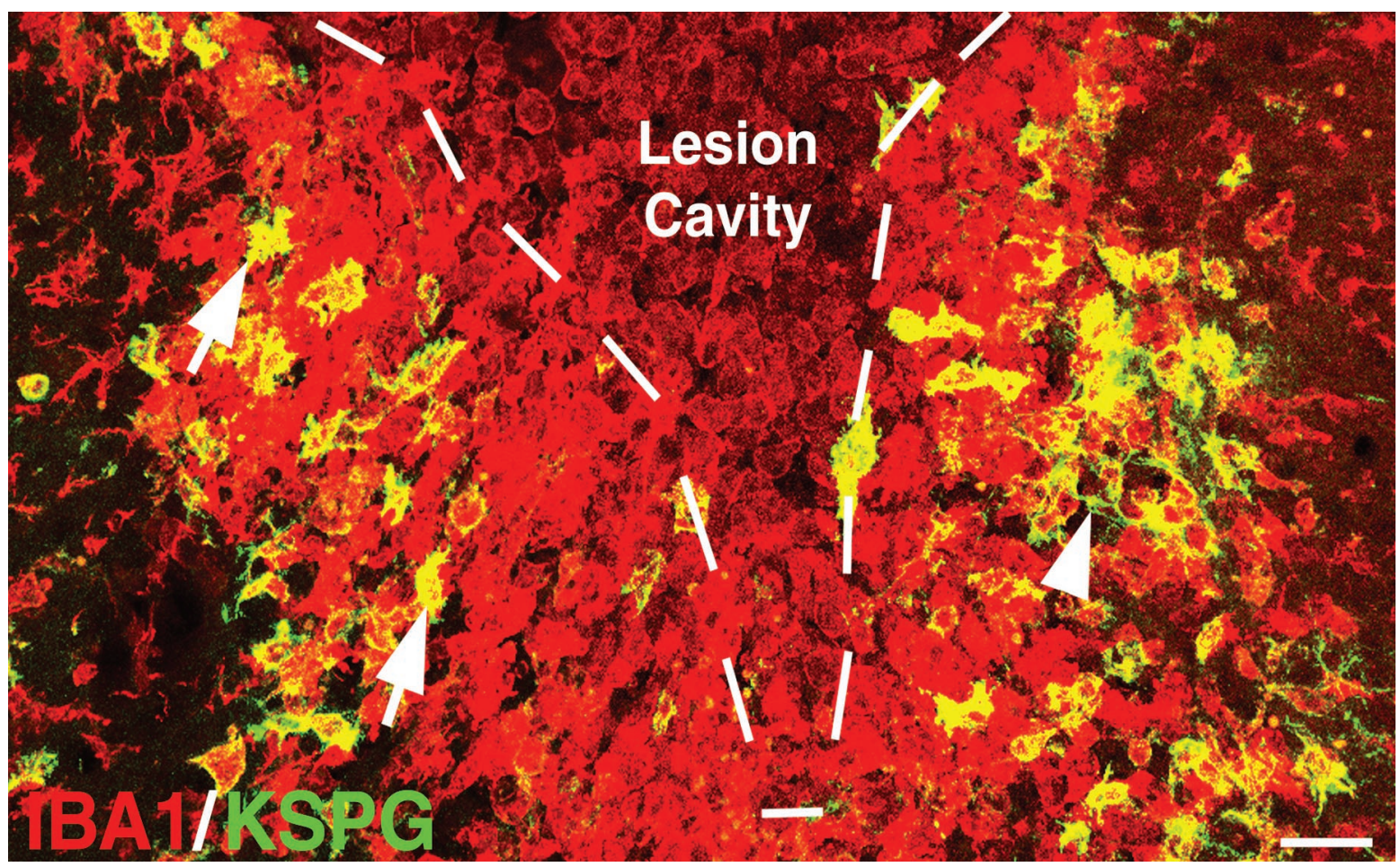

Figure 6. KSPG-labeled macrophages are present in the injured spinal cord parenchyma and not in the lesion cavity. A composite of two confocal images taken from a sagittal section $7 \mathrm{~d}$ after SCI is shown. The microglial/macrophage marker IBA1 is red, and 5D4-KSPG is green. 5D4-KSPG-labeled macrophages (arrows) occupy the injured tissue adjacent to the lesion site but are not present within the lesion cavity (white dashed arrows). The lesion cavity is filled with IBA1-labeled/5D4-KSPG-negative macrophages that may enter the lesion cavity from the blood after SCI. The arrowhead indicates an example of 5D4-KSPG-labeled cellular processes that are not associated with IBA1 immunolabeling. The section is positioned so that the left side is rostral to the lesion. Scale bar, $38 \mu \mathrm{m}$.

Among the potential mechanisms that may restrict successful axonal regeneration in the injured CNS is the deposition of inhibitory ECM molecules. Several putatively inhibitory ECM molecules are upregulated after CNS injury, including CSPGs (Levine, 1994; Fitch and Silver, 1997a; Haas et al., 1999; Lemons et al., 1999; McKeon et al., 1999; Chang et al., 2000; Thon et al., 2000; Yamaguchi, 2000; Jones et al., 2001). The purpose of the present study was to identify whether inhibitory ECM molecules belonging to the family of KSPGs are a prominent component of the injured spinal cord, thereby potentially contributing to inhibition of axonal growth. Our results demonstrate that 5D4-KSPG was constitutively expressed by a subpopulation of microglia in both the white and gray matter of the intact spinal cord. After SCI, 5D4-KSPG was rapidly and robustly expressed in and around the lesion site, peaking in expression $3 \mathrm{~d}$ after injury and gradually decreasing thereafter. During the 8 week postlesion period that was studied, 5D4-KSPG was expressed by macrophages and reactive microglia. Oligodendrocyte progenitor cells also showed a transient burst of expression of 5D4-KSPG at 3 and $7 \mathrm{~d}$ after SCI, contributing considerably to 5D4-KSPG deposition during the first week after injury. Astrocytes were not identified as a source of 5D4-KSPG. Together with potent inhibitory effects on neurite outgrowth in vitro (Snow et al., 1990b; Cole and
McCabe, 1991; Dou and Levine, 1995; Powell et al., 1997), these findings support the hypothesis that KSPG expression contributes to the creation of a nonpermissive extracellular milieu for axonal growth after SCI.

5D4-KSPG is expressed throughout the intact, adult CNS on highly ramified, resting microglia (Jander and Stoll, 1996; Bertolotto et al., 1998). This constitutive expression of 5D4-KSPG is present in approximately one-half of all microglia in the intact spinal cord (Fig. 4A,B). After SCI, 5D4-KSPG expression rapidly and robustly increased, but only in injured parenchymal cells located adjacent to the lesion site; 5D4-KSPG was not expressed by cells within the lesion cavity. Indeed, despite the fact that the lesion cavity was filled with IBA1-labeled macrophages $7 \mathrm{~d}$ after injury, 5D4-KSPG/IBA1 double-labeled cells were only present in spinal cord parenchyma surrounding the lesion site (Fig. 6). In addition, macrophages within the lesion cavity were densely packed, suggesting extravasation from a vascular source, unlike the less densely packed, interstitial pattern of IBA1 labeling in adjacent cord parenchyma. 5D4-KSPG/IBA1 double-labeled cells also exhibited oblong perikarya with ruffled membranes and short, stout processes, suggesting derivation from central microglia (Streit et al., 1988; Kreutzberg, 1996). Interestingly, peripheral blood macrophages that accumulate in the injured sciatic

$\leftarrow$

(Figure legend continued.) 5D4-KSPG (arrowheads). G-I, At $7 \mathrm{~d}$ after injury, a greater number of both IBA1-labeled cells ( $H)$ and IBA1-expressing 5D4-KSPG macrophages $(I)$ (arrows) is seen in comparison with early time points after injury. At this time point, the number of non-IBA1-labeled cells expressing 5D4-KSPG is considerably reduced in comparison with $3 \mathrm{~d}$ after SCI. $J-L$, By 8 weeks after injury, IBA1-labeled cells in the lesioned tissue have become more ramified; highly ramified cells are indicated with arrows; partially ramified are indicated with arrowheads. All photomicrographs represent tissue within $300 \mu \mathrm{m}$ of the lesion site. Scale bar, $11 \mu \mathrm{m}$. 

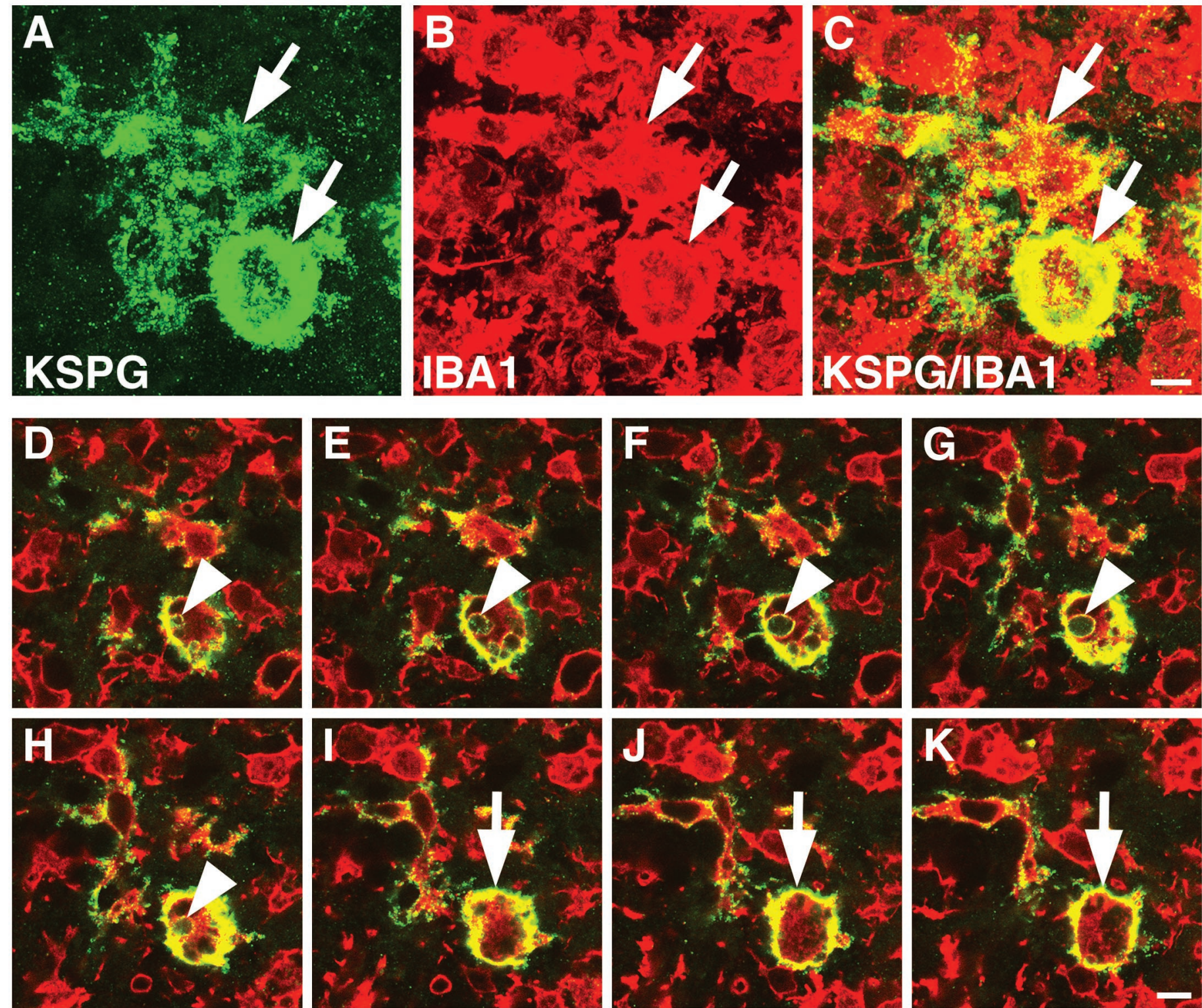

Figure 7. KSPG immunoreactivity is associated with the outer cellular surface of macrophages. $A-C$, Punctate KSPG immunoreactivity is specific to the outer surface (arrows) of macrophages and reactive microglia. Z-stack confocal images $7 \mathrm{~d}$ after SCI are shown. Scale bar, $6 \mu \mathrm{m}$. $D-K$, Serial sections, separated by $0.8 \mu \mathrm{m}$, show KSPG (green) covering the outer surface of an IBA1-labeled macrophage (red). Arrowheads indicate a phagocytic vacuole that still has KSPG attached to the cellular surface that was engulfed during phagocytosis. Arrows indicate 5D4-KSPG immunoreactivity specific to the outer cellular surface of an IBA1 labeled macrophage. Scale bar, $6 \mu \mathrm{m}$.

nerve do not express 5D4-KSPG (Jander and Stoll, 1996), further supporting the possibility that 5D4-KSPG-expressing macrophages in injured spinal tissue may be derived from microglia transformed into CNS macrophages, rather than originating from blood. Currently, there are no cellular markers that distinguish peripherally and centrally derived macrophages, and the relative amounts of these two subclasses of macrophages after CNS injury are unknown. In vitro application of macrophage colonystimulating factor (MCSF) and tumor necrosis factor- $\alpha$ (TNF- $\alpha$ ), two proinflammatory cytokines strongly upregulated after SCI (Streit et al., 1998), leads to retraction of microglial processes and increased expression of microglial 5D4-KSPG (Jander et al., 2000). Elevated levels of these proinflammatory cytokines have not been described in the intact, developing, or adult CNS (Pousset, 1994), potentially explaining why previous studies examining the developing brain only observed 5D4-KSPG expression on fully ramified microglia (Bertolotto et al., 1995). In addition, Giordana et al. (1994) report the accumulation of 5D4-KSPGlabeled cells of irregular shape, with oblong perikarya and occasional processes, in close proximity to a stab lesion in the cerebral hemisphere. These cells may also represent brain macrophages that are expressing 5D4-KSPG. Together, these data suggest that 5D4-KSPG-producing macrophages may originate from microglia, and thus be unique from blood-borne macrophages.

Oligodendrocyte progenitor cells exhibited dense but transient expression of 5D4-KSPG during the first week after SCI. Interestingly, we and others have reported previously that oligodendrocyte progenitors also produce the chondroitin sulfate proteoglycan NG2 after injury (Nishiyama et al., 1997; Redwine and Armstrong, 1998; Jones et al., 2001). Thus, this glial cell type 

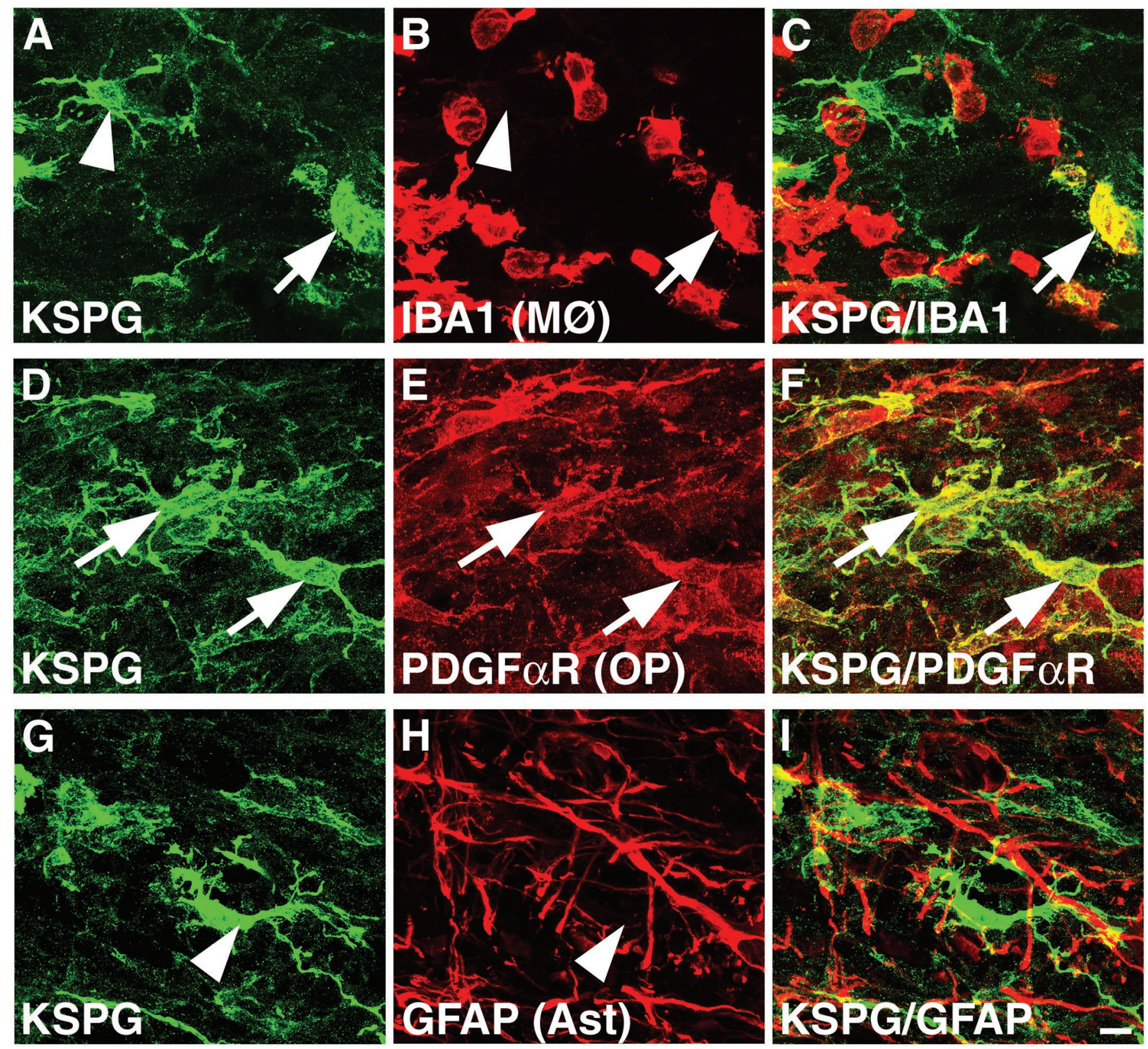

Figure 8. Oligodendrocyte progenitors are an additional source of KSPG after SCI. At 3 d after injury, Z-stack confocal images of 5D4-KSPG and different cellular markers define multiple cellular sources of 5D4-KSPG. $A-C, 5 \mathrm{D} 4-\mathrm{KSPG}$ is heavily expressed by macrophages $(M \emptyset)$ at the site of injury (arrows). Arrowheads indicate 5D4-KSPG immunoreactivity that is IBA1-negative. $D-F$, Immunolabeling for PDGF $\alpha$-receptor $(P D G F \alpha R)$ [cellular marker for oligodendrocyte progenitors $(O P)$ ] demonstrates that oligodendrocyte progenitors are an additional cellular source of 5D4-KSPG after SCI 5D4-KSPG immunoreactivity is present on the soma and processes of these cells. G-I, GFAP-labeled astrocytes (Ast) do not colocalize with 5D4-KSPG (arrowheads). Scale bar, $11 \mu \mathrm{m}$.

appears to have a propensity to express proteoglycan molecules after injury. The production of a series of proinflammatory cytokines after SCI, including MCSF, TNF- $\alpha$, interleukin- $1 \beta$ (IL$1 \beta$ ), IL-6, and transforming growth factor- $\beta$ (Semple-Rowland et al., 1995; Streit et al., 1998), could represent a signal to oligodendrocyte progenitors and other cells to alter ECM production.

We did not observe colocalization of 5D4-KSPG and GFAP immunoreactivity (Figs. $1 H-J, 8 G-I, 9 H-J$ ), suggesting that astrocytes are not sources of 5D4-KSPG after SCI. A recent in vitro study reported that astrocyte cell lines produce KSPGs (Powell and Geller, 1999), and a second study demonstrated that astro- cytes treated with keratanase, an enzyme that cleaves keratan sulfates from the core proteoglycans, increases neurite growth (Powell et al., 1997). Primary astrocytes, however, do not express 5D4-KSPG (Hirsch and Bahr, 1999). In vivo studies, in contrast, have reported that the KSPG ABAKAN is associated with astrocytes in the optic nerve (Geisert et al., 1992) and in the cerebral cortex after stab wounds in early postnatal rats (Geisert et al., 1996). Production of KSPGs by astrocytes after CNS injury in the adult has not been observed in this or previous studies, however, suggesting a reduction in the capacity of astrocytes to produce extracellular matrix from development to adulthood. 

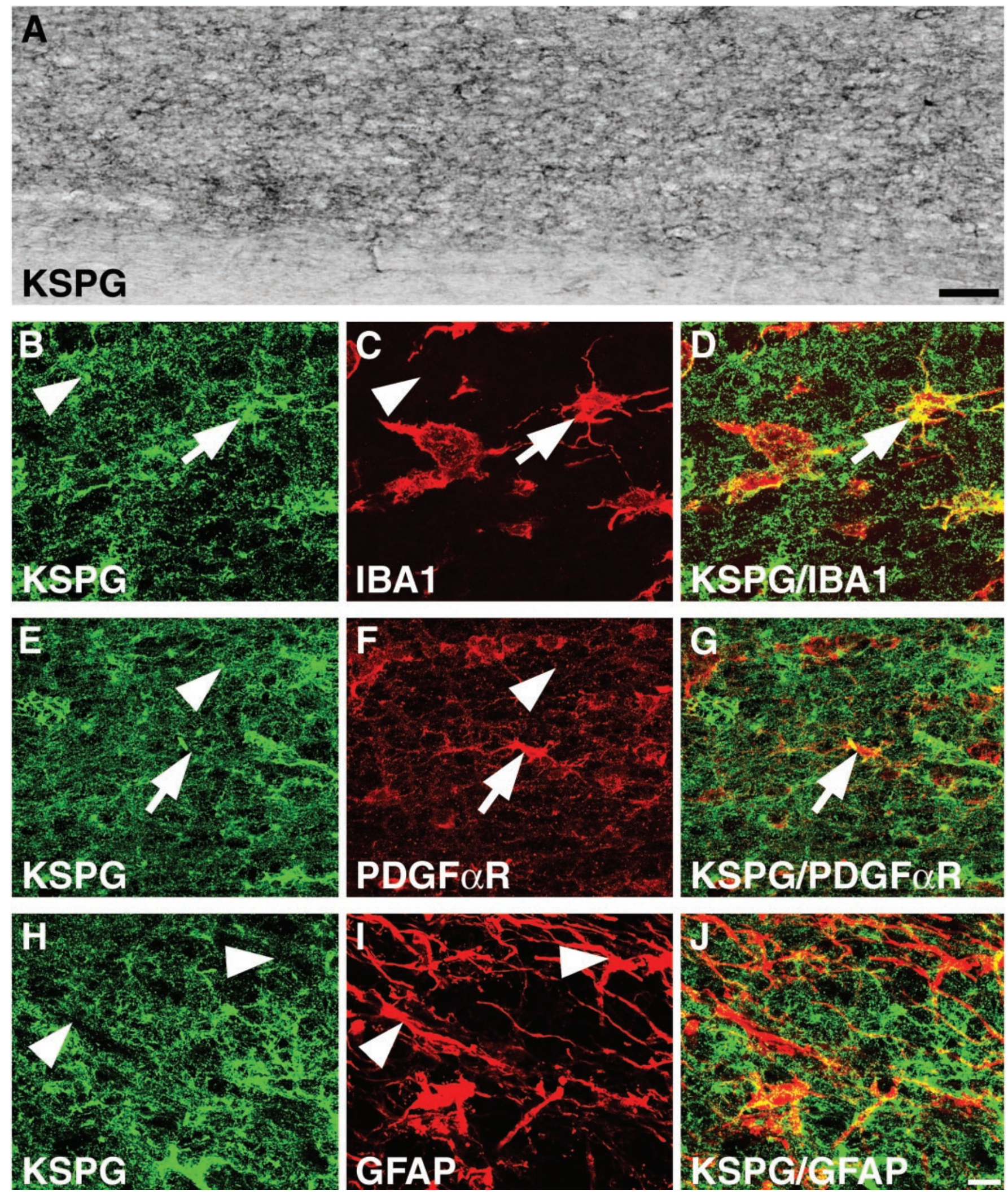

Figure 9. Cellular localization of KSPG expression in the degenerating dorsal columns. $A, 5 \mathrm{D} 4-\mathrm{KSPG}$ immunoreactivity is observed throughout the degenerating dorsal white matter at considerable distances from the lesion site $(5 \mathrm{~mm}) 2$ weeks after injury. Scale bar, $110 \mu \mathrm{m}$. $B-D$, 5D4-KSPG immunolabeling is specific to several ramified and reactive microglia throughout the degenerating tissue (arrows). A considerable amount of 5D4-KSPG immunoreactivity is also present that is not associated with IBA1 microglia (arrowheads). $E-G$, 5D4-KSPG immunolabeling is not as clearly associated with PDGF $\alpha$-receptor $(P D G F \alpha R)$ oligodendrocyte progenitors (arrows), in contrast to the clear association that was observed within the lesion site itself. Arrowheads indicate 5D4-KSPG-positive cellular profiles not associated with oligodendrocyte progenitor cells. $H-J$, GFAP-labeled astrocytes do not colocalize with 5D4-KSPG (arrowheads). Scale bar, $11 \mu \mathrm{m}$. 
In addition to KSPG expression at the injury site, 5D4-KSPG labeling was also detected in degenerating dorsal column white matter $5 \mathrm{~mm}$ distant from the injury site, likely as a result of continuing inflammation associated with axonal breakdown. However, this continued expression was associated with degenerating distal components of ascending sensory axons but not with the degenerating components of CST axons caudal to the lesion site. Interestingly, a recent study (Warden et al., 2001) demonstrated a considerably greater frequency of apoptosis in the ascending dorsal columns rostral to a lesion site than in the descending CST caudal to a lesion site. The same study also reported that apoptosis peaked $14 \mathrm{~d}$ after injury in the ascending dorsal columns, the same time point at which we observed a peak of 5D4-KSPG expression in the ascending dorsal columns. Production of KSPG in these degenerating tracts was associated with reactive microglia and macrophages and, possibly, oligodendrocyte progenitor cells; however, other cells also appeared to contribute to KSPG production in degenerating white matter.

The present findings, together with previous reports (Fitch and Silver, 1997b; Lemons et al., 1999; Jones et al., 2001; Lemons et al., 2001; Pasterkamp et al., 2001; Plant et al., 2001), demonstrate that the expression of ECM molecules after SCI is a dynamic process that may contribute to axonal growth failure. KSPGs probably contribute to this process, in addition to previously identified molecules involved in SCI, including the CSPG family members brevican, neurocan, NG2, versican, and phosphacan (Jones et al., 2001; Plant et al., 2001). A recent report indeed identifies the CSPGs versican and brevican as components of adult CNS white matter (Niederost et al., 1999), introducing the possibility that proteoglycans participate in limiting axonal regeneration in the white matter of the CNS. Interestingly, general degradation of CSPGs after brain injury (Moon et al., 2001) and after SCI (Bradbury et al., 2002) enhances axonal growth and generates partial functional recovery. A hypothesis to be explored by findings of the present study is that yet greater effects in promoting axonal regeneration might be achieved by the combined degradation of both keratan and chondroitin sulfate chains associated with the core proteoglycans after injury.

\section{REFERENCES}

Bertolotto A, Caterson B, Canavese G, Migheli A, Schiffer D (1993) Monoclonal antibodies to keratan sulfate immunolocalize ramified microglia in paraffin and cryostat sections of rat brain. $\mathrm{J}$ Histochem Cytochem 41:481-487.

Bertolotto A, Manzardo E, Iudicello M, Guglielmone R, Riccio A (1995) Keratan sulphate is a marker of differentiation of ramified microglia. Brain Res Dev Brain Res 86:233-241.

Bertolotto A, Agresti C, Castello A, Manzardo E, Riccio A (1998) 5D4 keratan sulfate epitope identifies a subset of ramified microglia in normal central nervous system parenchyma. J Neuroimmunol 85:69-77.

Bradbury EJ, Moon LD, King VR, Priestley JV, Fawcett JW, McMahon SB (2002) Chondroitinase ABC promotes functional recovery after spinal cord injury. Nature 416:636-640.

Caterson B, Christner JE, Baker JR (1983) Identification of a monoclonal antibody that specifically recognizes corneal and skeletal keratan sulfate. Monoclonal antibodies to cartilage proteoglycan. J Biol Chem 258:8848-8854.

Chang A, Nishiyama A, Peterson J, Prineas J, Trapp BD (2000) NG2positive oligodendrocyte progenitor cells in adult human brain and multiple sclerosis lesions. J Neurosci 20:6404-6412.

Cole GJ, McCabe CF (1991) Identification of a developmentally regulated keratan sulfate proteoglycan that inhibits cell adhesion and neurite outgrowth. Neuron 7:1007-1018.

Dou CL, Levine JM (1995) Differential effects of glycosaminoglycans on neurite growth on laminin and L1 substrates. J Neurosci 15:8053-8066.

Filbin MT (1995) Myelin-associated glycoprotein: a role in myelination and in the inhibition of axonal regeneration? Curr Opin Neurobiol 5:588-595.

Fitch MT, Silver J (1997a) Glial cell extracellular matrix: boundaries for axon growth in development and regeneration. Cell Tissue Res 290:379-384.

Fitch MT, Silver J (1997b) Activated macrophages and the blood-brain barrier: inflammation after CNS injury leads to increases in putative inhibitory molecules. Exp Neurol 148:587-603.

Geisert EE, Williams RC, Bidanset DJ (1992) A CNS specific proteoglycan associated with astrocytes in rat optic nerve. Brain Res 571:165-168.

Geisert EE, Bidanset DJ, Del Mar N, Robson JA (1996) Up-regulation of a keratan sulfate proteoglycan following cortical injury in neonatal rats. Int J Dev Neurosci 14:257-267.

Geisert Jr EE, Bidanset DJ (1993) A central nervous system keratan sulfate proteoglycan: localization to boundaries in the neonatal rat brain. Brain Res Dev Brain Res 75:163-173.

Giordana MT, Attanasio A, Cavalla P, Migheli A, Vigliani MC, Schiffer D (1994) Reactive cell proliferation and microglia following injury to the rat brain. Neuropathol Appl Neurobiol 20:163-174.

Grill R, Murai K, Blesch A, Gage FH, Tuszynski MH (1997) Cellular delivery of neurotrophin-3 promotes corticospinal axonal growth and partial functional recovery after spinal cord injury. J Neurosci 17:5560-5572.

Haas CA, Rauch U, Thon N, Merten T, Deller T (1999) Entorhinal cortex lesion in adult rats induces the expression of the neuronal chondroitin sulfate proteoglycan neurocan in reactive astrocytes. J Neurosci 19:9953-9963.

Hirsch S, Bahr M (1999) Immunocytochemical characterization of reactive optic nerve astrocytes and meningeal cells. Glia 26:36-46.

Huber AB, Schwab ME (2000) Nogo-A, a potent inhibitor of neurite outgrowth and regeneration. J Biol Chem 381:407-419.

Ito D, Imai Y, Ohsawa K, Nakajima K, Fukuuchi Y, Kohsaka S (1998) Microglia-specific localisation of a novel calcium binding protein, Iba1. Brain Res Mol Brain Res 57:1-9.

Jander S, Stoll G (1996) Downregulation of microglial keratan sulfate proteoglycans coincident with lymphomonocytic infiltration of the rat central nervous system. Am J Pathol 148:71-78.

Jander S, Schroeter M, Fischer J, Stoll G (2000) Differential regulation of microglial keratan sulfate immunoreactivity by proinflammatory cytokines and colony-stimulating factors. Glia 30:401-410.

Jones LL, Yamaguchi Y, Stallcup WB, Tuszynski MH (2001) NG2 is a major chondroitin sulfate proteoglycan produced after spinal cord injury and is expressed by macrophages and oligodendrocyte progenitors. J Neurosci 22:2792-2803.

Kloss CU, Werner A, Klein MA, Shen J, Menuz K, Probst JC, Kreutzberg GW, Raivich G (1999) Integrin family of cell adhesion molecules in the injured brain: regulation and cellular localization in the normal and regenerating mouse facial motor nucleus. J Comp Neurol 411:162-178.

Kreutzberg GW (1996) Microglia: a sensor for pathological events in the CNS. Trends Neurosci 19:312-318.

Lemons ML, Howland DR, Anderson DK (1999) Chondroitin sulfate proteoglycan immunoreactivity increases following spinal cord injury and transplantation. Exp Neurol 160:51-65.

Lemons ML, Sandy JD, Anderson DK, Howland DR (2001) Intact aggrecan and fragments generated by both aggrecanase and metalloproteinase-like activities are present in the developing and adult rat spinal cord and their relative abundance is altered by injury. J Neurosci 21:4772-4781.

Levine JM (1994) Increased expression of the NG2 chondroitin-sulfate proteoglycan after brain injury. J Neurosci 14:4716-4730.

McKeon RJ, Jurynec MJ, Buck CR (1999) The chondroitin sulfate proteoglycans neurocan and phosphacan are expressed by reactive astrocytes in the chronic CNS glial scar. J Neurosci 19:10778-10788.

McKerracher L, David S, Jackson DL, Kottis V, Dunn RJ, Braun PE (1994) Identification of myelin-associated glycoprotein as a major myelin-derived inhibitor of neurite growth. Neuron 13:805-811.

Miller B, Sheppard AM, Pearlman AL (1997) Developmental expression of keratan sulfate-like immunoreactivity distinguishes thalamic nuclei and cortical domains. J Comp Neurol 380:533-552.

Moon LD, Asher RA, Rhodes KE, Fawcett JW (2001) Regeneration of CNS axons back to their target following treatment of adult rat brain with chondroitinase ABC. Nat Neurosci 4:465-466.

Niederost BP, Zimmermann DR, Schwab ME, Bandtlow CE (1999) Bovine CNS myelin contains neurite growth-inhibitory activity associated with chondroitin sulfate proteoglycans. J Neurosci 19:8979-8989.

Nishiyama A, Lin XH, Giese N, Heldin CH, Stallcup WB (1996a) Co-localization of NG2 proteoglycan and PDGF $\alpha$-receptor on O2A progenitor cells in the developing rat brain. J Neurosci Res 43:299-314

Nishiyama A, Lin XH, Giese N, Heldin CH, Stallcup WB (1996b) Interaction between NG2 proteoglycan and PDGF $\alpha$-receptor on O2A progenitor cells is required for optimal response to PDGF. J Neurosci Res 43:315-330.

Nishiyama A, Yu M, Drazba JA, Tuohy VK (1997) Normal and reactive $\mathrm{NG} 2+$ glial cells are distinct from resting and activated microglia. J Neurosci Res 48:299-312.

Ohsawa K, Imai Y, Kanazawa H, Sasaki Y, Kohsaka S (2000) Involve- 
ment of IBA1 in membrane ruffling and phagocytosis of macrophages/ microglia. J Cell Sci 113:3073-3084.

Palfreyman JW, Thomas DG, Ratcliffe JG, Graham DI (1979) Glial fibrillary acidic protein (GFAP): purification from human fibrillary astrocytoma, development and validation of a radioimmunoassay for GFAP-like immunoactivity. J Neurol Sci 41:101-113.

Pasterkamp RJ, Anderson PN, Verhaagen J (2001) Peripheral nerve injury fails to induce growth of lesioned ascending dorsal column axons into spinal cord scar tissue expressing the axon repellent Semaphorin3A. Eur J Neurosci 13:457-471.

Perris R, Krotoski D, Lallier T, Domingo C, Sorrell JM, Bronner-Fraser M (1991) Spatial and temporal changes in the distribution of proteoglycans during avian neural crest development. Development 111:583-599.

Plant GW, Bates ML, Bunge MB (2001) Inhibitory proteoglycan immunoreactivity is higher at the caudal than the rostral Schwann cell graft-transected spinal cord interface. Mol Cell Neurosci 17:471-487.

Pousset F (1994) Developmental expression of cytokine genes in the cortex and hippocampus of the rat central nervous system. Brain Res Dev Brain Res 81:143-146.

Powell EM, Geller HM (1999) Dissection of astrocyte-mediated cues in neuronal guidance and process extension. Glia 26:73-83.

Powell EM, Fawcett JW, Geller HM (1997) Proteoglycans provide neurite guidance at an astrocyte boundary. Mol Cell Neurosci 10:27-42.

Redwine JM, Armstrong RC (1998) In vivo proliferation of oligodendrocyte progenitors expressing $\mathrm{PDGF} \alpha \mathrm{R}$ during early remyelination. J Neurobiol 37:413-428.

Semple-Rowland SL, Mahatme A, Popovich PG, Green DA, Hassler Jr G, Stokes BT, Streit WJ (1995) Analysis of TGF- $\beta 1$ gene expression in contused rat spinal cord using quantitative RT-PCR. J Neurotrauma 12:1003-1014.

Seo H, Geisert Jr EE (1995) A keratan sulfate proteoglycan marks the boundaries in the cortical barrel fields of the adult rat. Neurosci Lett 197:13-16.
Snow DM, Steindler DA, Silver J (1990a) Molecular and cellular characterization of the glial roof plate of the spinal cord and optic tectum: a possible role for a proteoglycan in the development of an axon barrier. Dev Biol 138:359-376.

Snow DM, Lemmon V, Carrino DA, Caplan AI, Silver J (1990b) Sulfated proteoglycans in astroglial barriers inhibit neurite outgrowth in vitro. Exp Neurol 109:111-130.

Stichel CC, Niermann H, D'Urso D, Lausberg F, Hermanns S, Muller HW (1999) Basal membrane-depleted scar in lesioned CNS: characteristics and relationships with regenerating axons. Neuroscience 93:321-333.

Streit WJ, Graeber MB, Kreutzberg GW (1988) Functional plasticity of microglia: a review. Glia 1:301-307.

Streit WJ, Semple-Rowland SL, Hurley SD, Miller RC, Popovich PG, Stokes BT (1998) Cytokine mRNA profiles in contused spinal cord and axotomized facial nucleus suggest a beneficial role for inflammation and gliosis. Exp Neurol 152:74-87.

Thon N, Haas CA, Rauch U, Merten T, Fassler R, Frotscher M, Deller T (2000) The chondroitin sulphate proteoglycan brevican is upregulated by astrocytes after entorhinal cortex lesions in adult rats. Eur J Neurosci 12:2547-2558.

Warden P, Bamber NI, Li H, Esposito A, Ahmad KA, Hsu CY, Xu XM (2001) Delayed glial cell death following wallerian degeneration in white matter tracts after spinal cord dorsal column cordotomy in adult rats. Exp Neurol 168:213-224.

Weidner N, Ner A, Salimi N, Tuszynski MH (2001) Spontaneous corticospinal axonal plasticity and functional recovery after adult central nervous system injury. Proc Natl Acad Sci USA 98:3513-3518.

Yamaguchi Y (2000) Chondroitin sulfate proteoglycans in the nervous system. In: Proteoglycans: structure, biology, and molecular interactions (Iozzo RV, ed), pp 379-402. New York: Marcel Dekker. 